\title{
Disulfoxide Ligands in Rhodium Catalyzed Asymmetric 1,4-Addition: First Studies and Future Directions
}

\author{
Ronaldo Mariz, ${ }^{\S}$ Justus Bürgi, Michele Gatti, Emma Drinkel, Xinjun Luan, and Reto Dorta*
}

§SCS Mettler-Toledo Award Winner (Oral Presentation)

\begin{abstract}
Disulfoxides with atropisomeric backbones are introduced as readily available chiral ligands for the rhodium-catalyzed 1,4-addition of arylboronic acids to unsaturated carbonyl compounds. The ligands are obtained in pure form from either commercially available or easily synthesized starting materials. Precatalysts with general formula $\{\text { (disulfoxide) } \mathrm{RhCl}\}_{2}$ were prepared in high yield and were fully characterized. Preliminary results on the influence of steric and electronic modifications of the ligand structure and their impact on the catalytic behavior are presented.
\end{abstract}

Keywords: 1,4-Addition · Chiral sulfoxide ligands · Ligand tuning · Rhodium catalysis

\section{Introduction}

While a plethora of chiral ligating entities for metals have been reported in the past, phosphorus- and nitrogen-based ligands play by far the most important role for stabilizing the relatively soft late-transition metal (LTM) centers. Perhaps due to the fact that organic sulfur-containing compounds are often thought to poison metals in catalytic cycles, LTMs that contain sulfur-based ligands have until now only played a minor role in (asymmetric) catalysis. ${ }^{[1]}$ Within the category of compounds that bind metals through their sulfur moiety, sulfoxides seem to be particularly appealing. These compounds already play an important role as chiral auxiliaries in asymmetric synthesis, ${ }^{[2]}$ in many cases having chiral discrimination associated with metal binding events involving either sulfur or oxygen (ambidentate ability), and studies on their basic coordination chemistry exist in the literature. ${ }^{[3-6]}$ Some potential advantages of sulfoxides are their inherent chirality at sulfur, their non-toxicity, the high stability to moisture and oxygen, as well as their facile synthesis in enantiomerically pure form.

We have recently started investigating the potential of chelating, sulfoxide-based compounds as ligands in asymmetric latetransition metal chemistry. ${ }^{[7]}$ The synthesis of atropisomeric disulfoxides, their complexation and first studies on their catalytic activity in metal-catalyzed organic transformations are described herein.

\section{Synthesis and Complexation}

The first disulfoxide ligand synthesized in our laboratory was a 1,1'-binaphthyl derivative similar to the well-known BINAP (1,1'-binaphthalene-2,2'-diyl-bisdiphenylphosphine) ligand developed by Noyori and coworkers. ${ }^{[8]}$ Following the original synthesis of BINAP, the dilithiated intermediate of racemic DBBN (rac-2,2'dibromo-1,1'-binaphthyl) was reacted with either $(+)-(1 S)$-menthyl-( $R)$ - or (-)-(1R)menthyl- $(S)-p$-toluenesulfinate (Scheme
1), to give a pair of diastereoisomers in 80$90 \%$ overall yield. It is important to mention that the two diastereoisomers formed can be easily separated via column chromatography, independently from whether $S$ - or $R$ sulfinates are employed. This renders the synthesis of $\mathbf{1}$ very straightforward and quantities of up to 20 grams can be easily synthesized in two working days.

In analogy to the nomenclature of BINAP and its derivatives, we name this ligand $p$-tol-BINASO $[1,1$ '-binaphthalene-2,2'-diyl-bis-( $p$-tolylsulfoxide), 1 ]. Ligand $\left[\left(P, R_{S}, R_{S}\right)-1\right]$ reacts readily with $\left[\mathrm{RhCl}\left(\mathrm{C}_{2} \mathrm{H}_{4}\right)_{2}\right]_{2}$ in methylene chloride at room temperature. ${ }^{\text {9] }}$ Crystallization from the concentrated reaction solution by layering THF at $-35^{\circ} \mathrm{C}$ afforded burgundy crystals of $\left[\left\{\left(P, R_{S}, R_{S}\right) \text { - } p \text {-tol-BINASO }\right\} \mathrm{RhCl}\right]_{2}$ (2) in high yield (>90\%). Figs 1 and 2 show the ORTEP drawings of both $\left(M, R_{S}, R_{S}\right)-p$ tol-BINASO $(\mathbf{1})$ and $\left[\left\{\left(P, R_{S}, R_{S}\right)-p\right.\right.$-tol-BI$\mathrm{NASO}\} \mathrm{RhCl}_{2}(2)$, allowing unambiguous assignment of the absolute configuration of all sites of the free ligand and the rhodiumcoordinated disulfoxide.

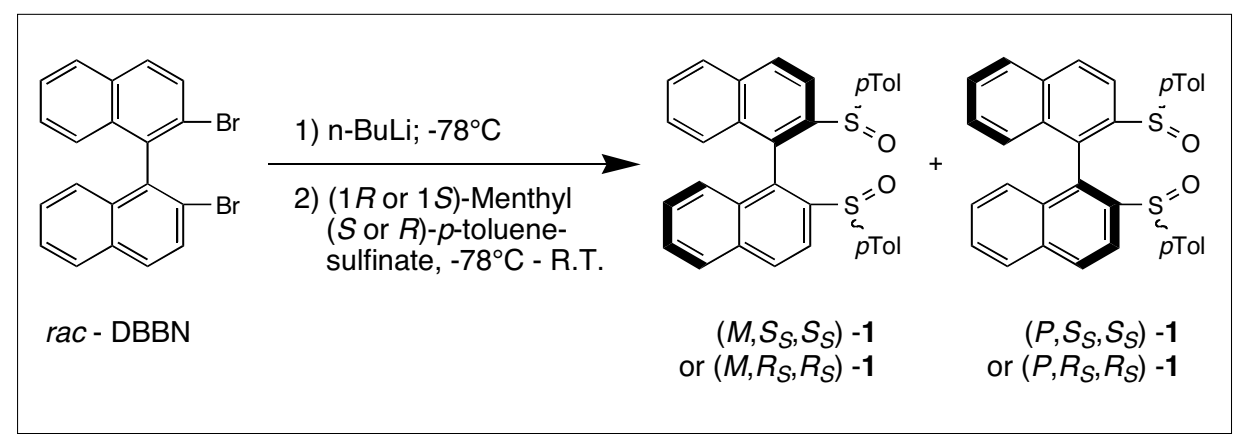

Scheme 1 . Synthesis of $p$-tol-BINASO from commercially available starting materials. 


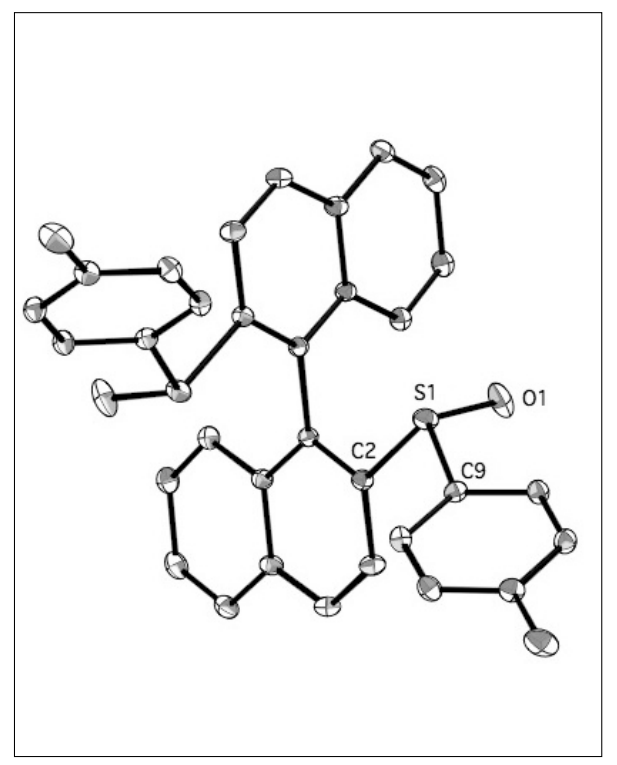

Fig. 1. ORTEP drawings (50\% probability) of $\left(M, R_{S}, R_{S}\right)$-p-tol-BINASO (1).

The Table compares selected bond lengths and angles of both the free ligand $\left(M, R_{S}, R_{S}\right)$-p-tol-BINASO (1) and the metal complex $\left[\left\{\left(P, R_{S}, R_{S}\right)\right.\right.$ - $p$-tol-BINASO $\} \mathrm{Rh}$ $\mathrm{Cl}]_{2}(2)$ with existing literature data for $(R)$ BINAP, ${ }^{[10]}$ and $[\{(R) \text {-BINAP }\} \mathrm{RhCl}]_{,}{ }^{[11]}$ While the sulfur-carbon and phosphorous-carbon bond distances differ only insignificantly in both the ligands and the complexes, the $\mathrm{S}-\mathrm{Rh}$ distances are slightly shorter than the corresponding $\mathrm{P}-\mathrm{Rh}$ bond lengths. This somewhat different bonding situation subsequently increases the bite angle of BINASO $\left(98.1^{\circ}\right)$ over BINAP $\left(90.5^{\circ}\right)$, whereas the dihedral angle between the planes of the two naphthyl units

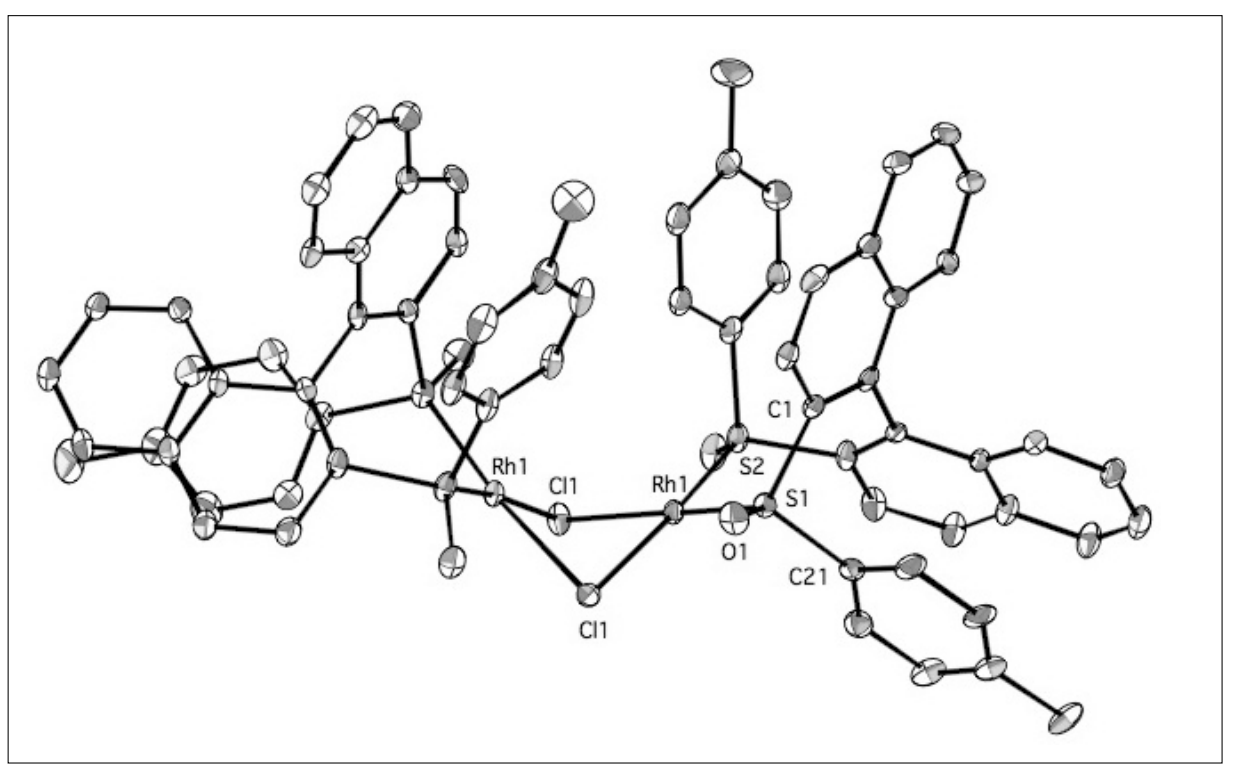

Fig. 2. ORTEP drawings (50\% probability) of $\left[\left\{\left(P, R_{S}, R_{S}\right)-p \text {-tol-BINASO }\right\} \text { RhCl }\right]_{2}$ (2).

remains very similar $\left(74.1^{\circ}\right.$ BINASO; $76.0^{\circ}$ BINAP). Finally, measurement of the $\mathrm{Rh} \cdots \mathrm{Rh}$ distances in $\mathbf{2}$ reveals a clearly more compact dimer than found for $[\{(R)$ BINAP $\} \mathrm{RhCl}_{2} \cdot{ }^{[12]}$

\section{First Catalytic Studies}

Since the first report on the asymmetric rhodium-catalyzed 1,4 -addition of boronic acids to enones by Miyaura and Hayashi employing BINAP,[13] a variety of ligands has been investigated for this transformation. ${ }^{[14]}$ With catalyst precursor 2 at hand and considering the obvious

Table. Select bond lengths $(\AA)$ and angles (deg) for free ligands and Rhodium complexes.

\section{$\left(M, R_{s}, R_{s}\right)$-p-tol-BINASO}

$$
\text { S1-01 1.4922(16) }
$$

O1-S1-C9 105.78(9)

$$
\text { S1-C2 } 1.7959 \text { (18) }
$$

S1-C9 1.7889 (18)

O1-S1-C2 106.16(9)

C9-S1-C2 101.92(8)

\section{$\left[\left\{\left(P, R_{s}, R_{s}\right)-p \text {-tol-BINASO }\right\} R{ }^{2}\right]_{2}$}

$$
\text { S1-01 1.466(4) }
$$

Rh1-S1 2.1942(13)

S2-Rh1-S1 98.14(4)

$\mathrm{P} 1-\mathrm{C} 11.830(5)$

C1-P1-C31 103.5(2)

P1-C1 1.862(6)

Rh1-P1 2.2144(17)

P1-Rh1-P2 90.20(6)

$$
\text { S1-C1 1.802(5) }
$$

S1-C21 1.782(5)

Rh1-S2 2.1893(12)

Cl1-Rh1-Cl1 81.80(6)

\section{(R)-BINAPa}

P1-C31 1.819(5)

C1-P1-C41 101.4(2)

\section{[\{(R)-BINAP\}RhCl] ${ }_{2}^{a}$}

$$
\text { P1-C51 1.844(6) }
$$

Rh1-P2 2.2056(16)

Cl1-Rh1-Cl2 80.45(5)
P1-C61 1.813(6)

P1-C61 1.813(6)

Rh1…Rh1 3.0194(7)

Rh1-Cl1-Rh1 78.94(4)

C31-P1-C41 103.3(3)

$\mathrm{Rh} 1 \cdots \cdot \mathrm{Rh} 23.2874(7)$

Cl1-Rh1-Cl2 80.45(5)

${ }^{a}$ Numbering of atoms has been taken from refs. [10] and [11] respectively.

structural similarity between the two systems, we reasoned that the 1,4-addition reaction could represent a very convenient model for our first catalytic activity studies.

Following the protocol applied using BINAP as ligand, initial experiments with catalyst $2(3 \mathrm{~mol} \%)$ were carried out in a mixture of dioxane/water/ $\mathrm{KOH}$ for the coupling of phenylboronic acid and 2-cyclohexenone and gave excellent selectivities $(98 \%$ ee $)$, but low overall yields $(<30 \%)$. Gratifyingly, substituting dioxane with toluene leads to complete conversion to the product within 30 minutes at room temperature while maintaining the high ee values. Further optimization of the reaction conditions showed that catalyst loadings could be lowered to $1.5 \mathrm{~mol} \% \mathrm{Rh}$ without significant loss of reactivity. In addition, the catalytic system does not require excess of expensive arylboronic acid and can be run with almost stoichiometric amounts at $40{ }^{\circ} \mathrm{C}$ (Scheme 2).

Using these optimized conditions, a number of arylboronic acids were screened with 2-cyclohexenone. Excellent yields and selectivities were achieved with a wide variety of ortho-, meta- and para-substituted arylboronic acids, containing both electron-withdrawing or electron-donating groups. Enones with different ring sizes and also a cyclic ester reacted with $\mathrm{PhB}(\mathrm{OH})$ and gave the same high level of yield and enantioselectivity. It should be noted that the selectivities and reactivities observed are among the highest for the rhodiumcatalyzed asymmetric 1,4-addition. More importantly, commercially available starting materials can be used without purification, thus confirming the robustness of the catalyst precursor towards common impurities. [7] 

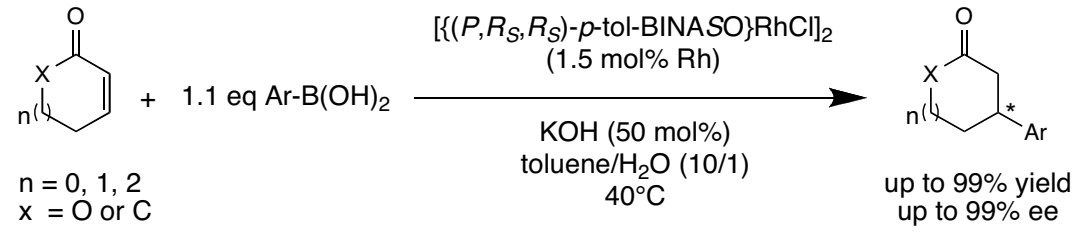

Scheme 2. Optimized conditions for 1,4-addition using rhodium(disulfoxide) complex 2.

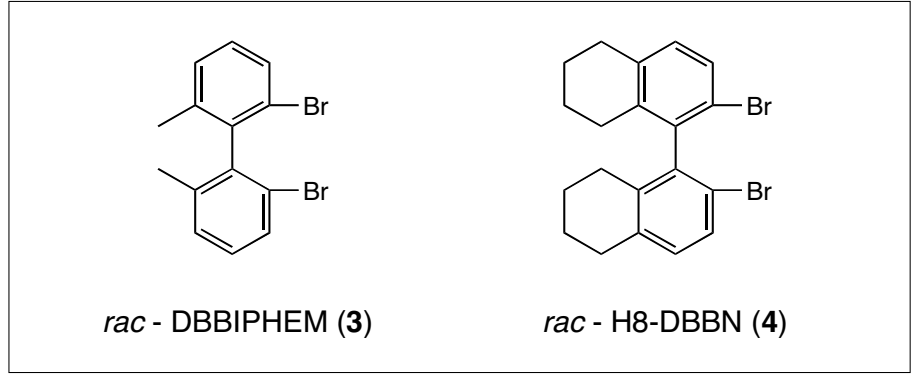

Fig. 3. Atropisomeric racemic dibromoderivatives used as backbones for modified bis-sulfoxide ligands.

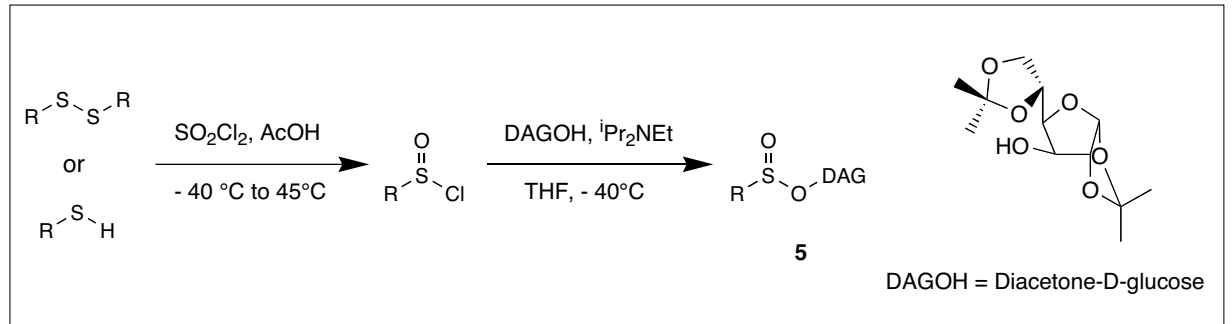

Scheme 3. DAG methodology applied for the synthesis of new sulfinates.

\section{Ligand Modifications}

It is well known that both structural and electronic parameters influence the properties of a catalytically active metal center. ${ }^{[15,16]}$ Encouraged by the exciting results obtained with our first catalytic system, we started to investigate the impact of such ligand tuning in atropisomeric disulfoxides. In analogy to research done with atropisomeric diphosphines, we introduced two modified backbones, 3 and $\mathbf{4}$ (Fig. 3). The synthesis of the new racemic dibromo-derivatives were carried out using well-established methods. ${ }^{[17]}$

To analyze the effect of these new backbones $(\mathbf{3}, \mathbf{4})$ on the reactivity and selectivity of the disulfoxide ligands, we used the same commercially available sulfinates employed for the synthesis of $\mathbf{1}$. Treatment of the brominated starting materials $\mathbf{3}$ and 4 with magnesium in a refluxing toluene/ THF mixture afforded the corresponding di-Grignard reagents, ${ }^{[17 b]}$ and subsequent addition of $p$-toluene-menthyl sulfinate at $-20{ }^{\circ} \mathrm{C}$ gave pairs of diastereoisomers that could again be easily separated by column chromatography.

Complexation of these ligands following the same procedure used for the syn- thesis of 2 leads to the formation of both the biphenyl and partially hydrogenated binaphthyl (disulfoxide)rhodium dimers in high yield $(>95 \%)$. These new precatalysts seem to be even more reactive and selective for the model reaction between phenylboronic acid and 2-cyclohexenone, giving virtually enantiopure products in short reaction times using lower catalyst loadings than necessary for 2 .

In order to tune the ligand framework at the sulfinyl moiety, we applied the DAG (diacetone-D-glucose) methodology to synthesize new sulfinates (Scheme 3). This route affords a general enantiodivergent approach for the synthesis of both enantiomers of a large number of alkyl and aryl sulfinates. ${ }^{[18]}$

It is well established that relatively small para-substituents in aryl phosphorus compounds do not affect the steric properties of a given ligand. ${ }^{[19]}$ If the same can be postulated for sulfoxides, the addition of electron-withdrawing or electron-donating groups in the para-position of the aromatic ring will allow us to compare the electronic influence of these substituents. Using DBBN as the backbone framework, we therefore generated a small library of ligands derived from sulfinates $\mathbf{5}$. Purifica- tion and complexation of these derivatives seems not to be significantly different and first catalytic experiments show that electronic factors do indeed play an important role. We hope that future studies will reveal trends that may be used for optimizing the disulfoxide ligand framework further.

\section{Summary and Outlook}

Chelating disulfoxides based on chiral atropisomeric backbone structures have been prepared. First catalytic studies show very high activities and selectivities in the rhodium-catalyzed 1,4-addition of arylboronic acids to cyclic $\alpha, \beta$-unsaturated ketones and esters, all the while using only stoichiometric amounts of expensive boronic acids. ${ }^{[7]}$

A detailed study is being carried out on the tuning of steric and electronic properties of these ligands. Our initial results on ligand modifications indicate that disulfoxides are not only synthetically versatile, but also susceptible to ligand design optimization. A compilation of results summarizing the synthesis, complexation and catalytic performance in the rhodium catalyzed 1,4-addition with these new atropisomeric disulfoxides will be published in due course as part of a broader research effort aimed at determining the potential of this ligand family.

\section{Acknowledgement}

This work was supported by the Swiss National Science Foundation (grant to R. M.), the Roche Research Foundation (grant to E. D.) and the Organic Chemistry Institute of the University of Zurich. R. D. is the recipient of an Alfred Werner Assistant Professorship and thanks the foundation for generous financial support. R. D. and R. M. are grateful to the SCS for the invitation to present the work.

Received: December 23, 2008

[1] For recent reviews on sulfide/sulfoxide ligands in catalysis, see: a) J. C. Bayon, C. Claver, A M. Masdeu-Bulto, Coord. Chem. Rev. 1999, 193-195, 73; b) A. M. Masdeu-Bulto, M. Dieguez, E. Martin, M. Gomez, Coord. Chem. Rev. 2003, 242, 159; c) M. Mellah, A. Voituriez, E. Schulz, Chem. Rev. 2007, 107, 5133.

[2] a) A. L. Walker, Tetrahedron Asymmetry 1992 , 3, 961; b) M. C. Carreno, Chem. Rev. 1995, 95, 1717; c) H. Pellissier, Tetrahedron 2006, 62, 5559.

[3] M. Calligaris, O. Carugo, Coord. Chem. Rev. 1996, 153, 83 .

[4] For achiral catalysis with sulfoxide ligands, see: a) Y. M. Y. Haddad, H. B. Henbest, J. Husbands, T. R. B. Mitchell, J. Trocha-Grimshaw, J. Chem. Soc., Perkin Trans. I 1974, 596; b) B. R. James, R. H. J. Morris, Chem. Soc., Chem. Commun. 1978, 929; c) H. Greenberg, A. Gogoll, J.-E. Bäckvall, J. Org. Chem. 1991, 56, 5808; d) R. C. Larock, R. Hightower, L. A. Hasvold, K. P. Peterson, J. Org. Chem. 1996, 61, 3584; e) M. S. Chen, M. C. White, J. Am. Chem. Soc. 2004, 126, 1346; f) K. J. Fraunhoffer, N. Prabagaran, 
L. E. Sirois, M. C. White, J. Am. Chem. Soc. 2006, 128, 9032.

[5] For attempts showing low selectivities/ reactivities: a) B. R. James, R. S. McMillan, Can. J. Chem. 1977, 55, 3927; b) N. Khiar, I. Fernandez, F. Alcudia, Tetrahedron Lett. 1993 , 34, 123; c) R. Tokunoh, M. Sodeoka, K. Aoe, M. Shibasaki, Tetrahedron Lett. 1995, 36, 8035.

[6] For somewhat better selectivities using sulfoxide/nitrogen or sulfoxide/phosphine chelates, see: a) J. V. Allen, J. F. Bower, J. M. J. Williams, Tetrahedron: Asymm. 1994, 5 , 1895; b) K. Hiroi, Y. Suzuki, Tetrahedron Lett. 1998, 39, 6499; c) K. Hiroi, Y. Suzuki, I. Abe Y. Hasegawa, K. Suzuki, Tetrahedron: Asymm. 1998, 9, 3797; d) D. G. I. Petra, P. C. J. Kamer, A. L. Spek, H. E. Schoemaker, P. W. N. M van Leeuwen, J. Org. Chem. 2000, 65, 3010, e) K. Hiroi, Y. Suzuki, I. Abe, R. Kawagishi, Tetrahedron 2000, 56, 4701; f) K. Hiroi, I. Izawa, T. Takizawa, K. Kawai, Tetrahedron 2004, 60, 2155.

[7] R. Mariz, X. Luan, M. Gatti, A. Linden, R. Dorta, J. Am. Chem. Soc. 2008, 130, 2172.

[8] A. Miashita, A. Yasuda, H. Takaya, K. Toriumi, T. Ito, T. Souchi, R. Noyori, J. Am. Chem. Soc. 1980, 102, 7933 .

[9] Its enantiomer $\left(M, S_{S}, S_{S}\right) \mathbf{- 1}$ also reacts readily with the $\mathrm{Rh}$ precursor, whereas $\left(M, R_{S}, R_{S}\right)-\mathbf{1}$ and $\left(P, S_{S}, S_{S}\right)-\mathbf{1}$ do not react cleanly to give the corresponding complexes. In this case, the tolyl groups on the sulfoxides hinder formation of the dimer, a phenomenon that is also observed for atropisomeric diphosphine ligands incorporating bulky aromatic groups on phosphorous, see: T. Ohshima, H. Tadaoka, K. Hori, N. Sayo, K Mashima, Chem. Eur. J. 2008, 14, 2060.

[10] A. J. Deeming, D. M. Speel, M. Stchedroff, Organometallics 1997, 16, 6004

[11] K. A. Bunten, D. H. Farrar, A. J. Poe, A. Lough, Organometallics 2002, 21, 3344.

[12] For comparative studies on the binding ability of sulfoxides to LTMs: a) D. R. Evans, M. Huang, W. M. Seganish, J. C. Fettinger, T. L.
Williams, Inorg. Chem. Commun. 2003, 6, 462. b) R. Dorta, H. Rozenberg, L. J. W. Shimon, D. Milstein, Chem. Eur. J. 2003, 9, 5237.

[13] Y. Takaya, M. Ogasawara, T. Hayashi, M. Sakai, M. Miyaura, J. Am. Chem. Soc. 1998, 120, 5579.

[14] For a review, see: a) T. Hayashi, K. Yamasaki, Chem. Rev. 2003, 103, 2829. With BINAP and its derivatives, see: b) S. Sakuma, M. Sakai, R. Itooka, N. Miyaura, J. Org. Chem. 2000, 65 , 5951; c) J.-P. Genet, Synlett 2002, 11, 1791; d) M. Pucheault, S. Darses, J.-P. Genet, Eur. J. Org. Chem. 2002, 3552; e) R. Itooka, Y. Iguchi, N. Miyaura, J. Org. Chem. 2003, 68, 6000. With phosphoramidites and phosphonites, see: f) M. T. Reetz, D. Moulin, A. Gosberg, Org. Lett. 2001, 3, 4083; g) J.-G. Boiteau, R. Imbos, A. J. Minaard, B. L. Feringa, Org. Lett. 2003 5, 681; h) J.-G. Boiteau, A. J. Minaard, B. L. Feringa, J. Org. Chem. 2003, 68, 9481; i) S. L. X. Martina, A. J. Minaard, B. Hessen, B. L. Feringa, Tetrahedron Lett. 2005, 46, 7159; j) K. Kurihara, N. Sugushita, K. Oshita, D. Piao, Y. Yamamoto, N. Miyaura, J. Organomet. Chem. 2007, 692, 428. With chiral dienes: k) T. Hayashi, K. Ueyama, N. Tokunaga, K. Yoshida, J. Am. Chem. Soc. 2003, 125, 11508; 1) C. Defieber, J.-F. Paquin, S. Serna, E. M. Carreira, Org. Lett. 2004, 6, 3873; m) J.-F. Paquin, C. Defieber, C. R. J. Stephenson, E. M. Carreira, J. Am. Chem. Soc. 2005, 127, 10850; n) Y. Otomaru, K. Okamoto, R. Shintani, T. Hayashi, J. Org. Chem. 2005, 70, 2503; o) J.F. Paquin, C. R. J. Stephenson, C. Defieber, E. M. Carreira, Org. Lett. 2005, 7, 3821; p) A. Kina, K. Ueyama, T. Hayashi, Org. Lett. 2005 , 7, 5889; q) F.-X. Chen, A. Kina, T. Hayashi, Org. Lett. 2006, 8, 341; r) T. Nishimura, M. Nagaosa, T. Hayashi, Chem. Lett. 2008, 37, 860; s) T. Gendrineau, O. Chuzel, H. Eijsberg, J.-P. Genet, S. Darses, Angew. Chem. Int. Ed. 2008, 47, 7669. With chiral P-olefin ligands: t) R. Shintani, W.-L. Duan, T. Nagano, A. Okada, T. Hayashi, Angew. Chem. Int. Ed. 2005, 44,
4611; u) E. Piras, F. Läang, H. Rüegger, D. Stein, M. Wörle, H. Grützmacher, Chem. Eur. J. 2006, 12, 5849; v) P. Kasak, V. B. Arion, M Widhalm, Tetrahedron: Asymmetry 2006, 17, 3084; w) W.-L. Duan, H. Iwamura, R. Shintani, T. Hayashi, J. Am. Chem. Soc. 2007, 129, 2130; y) R. Mariz, A. Briceno, R. Dorta, R. Dorta, Organometallics 2008, 27, 6605.

[15] a) 'Comprehensive Organometallic Chemistry', Eds. E. W. Abel, F. G. A. Stone, G. Wilkinson, Pergamon Press, Oxford, Vol. 12, 1995; b) R. H. Crabtree, 'The Organometallic Chemistry of the Transition Metals', Wiley, New York, 1994; c) W. R. Moser, D. W. Slocum, 'Homogeneous Transition Metal Catalyzed Reactions', Eds. Adv. Chem. Ser. 230, 1992; d) 'Applied Homogeneous Catalysis with Organometallic Compounds', Eds. B. Cornils, W. A. Herrmann, $\mathrm{VCH}$, Weinheim, 1996.

[16] For interesting investigations on the relationship between bite angle and electronic structure see: a) P. Hofmann, C. Meier, U. Englert, M. U. Schmidt, Chem. Ber. 1992, 125, 353; b) Z. Freixa, P. W. N. M. van Leeuwen, Dalton Trans. 2003, 1890.

[17] a) R. Schmid, M. Cereghetti, B. M. Heiser, P. Schönholzer, H.-J. Hansen, Helv. Chim. Acta 1988, 71, 897; b) X. Zhang, K. Mashima, K. Koyano, N. Sayo, H. Kumobayashi, S. Akutagawa, H. Takaya, Tetrahedron Lett. 1991 32, 7283 .

[18] I. Fernández, N. Khiar, J. M. Llera, F. Alcudia J. Org. Chem. 1992, 57, 6789.

[19] a) C. A. Tolman, Chem. Rev. 1977, 77, 312; b) T. L. Brown, Inorg. Chem. 1995, 34, 2718; c) R. S. Drago, S. Joerg, J. Am. Chem. Soc. 1996 118, 2654; d) A. Fernandez, C. Reyes, M. R. Wilson, D. C. Woska, A. Prock, W. P. Giering, Organometallics 1997, 16, 342; e) S. Joerg, R. S. Drago, J. Sales, Organometallics 1998, 17, 589. 